\title{
ENEOLITICKÝ SÍDELNÝ AREÁL V PODOLÍ PRI NOVOM MESTE NAD VÁHOM ${ }^{1}$
}

\author{
J A N A M E L L E R OVÁ ŠU T E K OVÁ
}

\begin{abstract}
Eneolithic Settlement Area in Podolie near Nové Mesto nad Váhom. The study presents the current state of the research in Podolie, at the site Horné Brežné (district Nové mesto nad Váhom). In 1963 the archaeological excavation unearthed two ditches with a large amount of Bošáca pottery situated on a loess promontory elevated above a river paleomeander. In the $21^{\text {st }}$ century a non-destructive survey was carried out and thanks to it, another enclosure with three parallel linear objects was discovered, with a total length of around $250 \mathrm{~m}$. This is the first time an interpretation of ditches based on the results of magnetometric prospection in Podolie is being published in archaeological journals and its purpose is also to form a scientific basis for follow-up theoretical and field research at the site. This paper also discusses the settlement strategies in time of Early Prehistory in south-eastern slopes of Little Carpathians.
\end{abstract}

Keywords: SW Slovakia, Little Carpathians, Neolithic, Eneolithic, Bronze Age, settlement area, circular enclosure, ditch.

\section{ÚVOD}

Nálezy bošáckej keramiky z katastra obce v Podolí v okrese Nové mesto nad Váhom pochádzajúce $\mathrm{z}$ dvoch priekop situovaných na hrane terénnej vlny, sprašového ostrohu, sú v archeologickej literatúre známe najneskôr od 70. rokov 20. storočia. Terénny výskum $\mathrm{v}$ polohe zvanom Španiva, v súčasnosti Horné Brežné, realizovala V. Němejcová-Pavúková v roku 1963, kedy odkryla dva priekopové útvary $\mathrm{v}$ dížke 50 metrov $\mathrm{s}$ jedným pät metrovým prerušením. Priekopy ohraničovali pomerne malý priestor úplne na konci ostrohu vyčnievajúcom nad paleomeander v súčasnosti zaniknutého vodného toku. Výskum priniesol vel'ké množstvo keramického materiálu, iných artefaktov a zvieracích kostí, ktorý ešte aj v súčasnosti predstavuje najväčší bošácky nálezový súbor na Slovensku. Spracovaniu nálezov, interpretácii archeologicko-kultúrneho obrazu sa venuje autorka tejto štúdie (Šuteková 2008; 2010, tamže vyhodnotenie a čiastkové výsledky). Základná práca s dokumentáciu terénneho výskumu z roku 1963 a absencia plánu zamerania celkovej situácie vo vztahu $\mathrm{k}$ okoliu vyvolala potrebu archeogeofyzikálneho prieskumu na lokalite, s cielom presnej lokalizácie predmetných priekop. Merania boli realizované v dvoch etapách Katedrou aplikovanej a environmentálnej geofyziky na Prírodovedeckej fakulte Univerzity Komenského v Bratislave, neskôr v roku 2011 v spolupráci s Institut für Gephysik, Christian-Albrechts-Univer- sität zu Kiel v Nemecku. Vd’aka nim sa podarilo lokalizovat miesto archeologického výskumu a obe krídla priekopy. Geofyzikálny prieskum v rozsahu skoro 4 ha zachytil však d’alší vel'ký líniový útvar v podobe troch rovnobežných lineárnych anomálií $\mathrm{v}$ tvare poloblúka ohraničujúceho vel'kú plochu terasy s koncami zvažujúcimi sa $\mathrm{k}$ jej krajom. Prvé predbežné výsledky boli publikované vzápätí kolektívom autorov M. Bošanský, H. Stümpel, T. Wunderlich, M. Proksch, R. Pašteka a J. Mellnerová Šuteková (Bošanský a i. 2012), pričom celkové zhodnotenie výsledkov realizovaných geofyzikálnych meraní sa pripravuje $\mathrm{v}$ blízkej budúcnosti. V archeologickej literatúre sú tieto výsledky publikované prvýkrát (obr. 1). Ďalšie objavené líniové štruktúry predstavujú pravdepodobne t. č. jediný takýto útvar známy z územia Slovenska, z formálneho hladiska s analógiami západne od Karpát v post-rondelovej kultúrnej krajine.

\section{PODOLIE, POLOHA HORNÉ BREŽNÉ - ARCHEOLOGICKÁ LOKALITA V KRAJINE}

Územie Podolia leží na východnom úpätí Čachtických Karpát, na sprašovej terase, ktorá bola v minulosti obmývaná meandrujúcimi malokarpatskými potokmi, prítokmi Dudváhu. Z geomorfologického hladiska ide o severný výbežok Podunajskej pahorkatiny, ktorá sa pri Novom meste nad Váhom vkliňuje medzi severnú čast’ Malých Karpát a Považský Inovec

\footnotetext{
1 Táto práca bola podporená Agentúrou na podporu výskumu a vývoja na základe Zmluvy č. APVV-14-0550 a projektom VEGA č. 1/0100/19.
} 


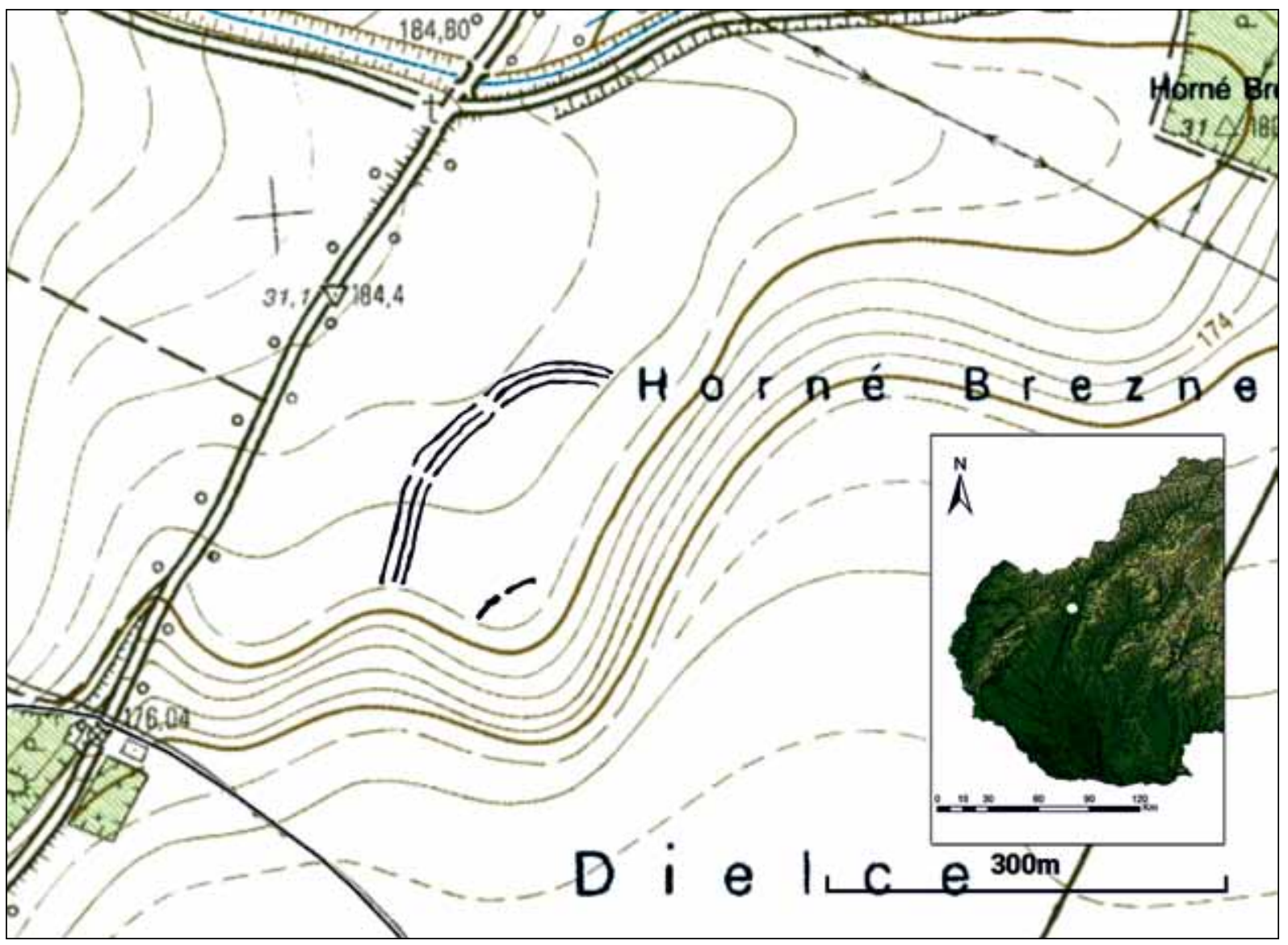

Obr. 1. Podolie, poloha Horné Brežné. Rekonštrukcia pôdorysu priekopy bošáckej kultúry a priekopového areálu (kresba J. Mellnerová Šuteková, zdroj mapového podkladu ZBGIS).

do priestoru v šírke necelých osem kilometrov. $\mathrm{Na}$ tom mieste, opúštajúc Považské Podolie Slovensko-moravských Karpát, vteká Váh zo severu do rozširujúcej sa roviny juhozápadného Slovenska a spomaluje prúdenie. $V$ historických obdobiach vytváral s prítokmi siet meandrov a mokradí a územie až do regulácie pravidelne zaplavoval. Riečne podložie predstavujú holocénne fluviálne sedimenty, ktoré sa naplavovali v severo-južnom smere a menili pleistocénne viate sprašové terasy. Pre rieku Váh bolo vo svojom dolnom toku typické vytváranie tzv. agradačného valu, náplavových vyvýšenín, ktoré patria $\mathrm{k}$ miestam $\mathrm{s}$ dobrými podmienkami na osídlenie $\mathrm{v}$ nížinách (napr. Bialeková 1990, 115-119; Ištok/Ižóf 1990). Vztah osídlenia k hydrologickým pomerom je dobre spracovaný na príklade mladšieho osídlenia $\mathrm{z}$ doby rímskej a stredoveku v okolí Pobedimskej aglomerácie. Sídla sa od včasného stredoveku koncentrovali na vyššie položenom agradačnom vale a brehoch meandrujúceho ramena Váhu (Bialeková 1990, obr. 1). Sídliská v Pobedime boli situované v centre alúvia s mokrad’ami v súčasnej nadmorskej výške okolo
$166,2 \mathrm{~m}$ n. m. a ležia len 2,5 km juhovýchodne od nami sledovanej sprašovej ostrohy v Podolí, ktorá v súčasnosti prevyšuje terén od najnižšieho bodu v alúviu o necelých 14 metrov. O historických hydrologických pomeroch napovedajú aj názvy Brehy, Brežné, Ostrovské, Niva a i., ktoré poukazujú na vztah $\mathrm{k}$ miestnym vodným tokom. Kataster Podolia patrí $\mathrm{k}$ archeologickým lokalitám (obr. 2: B) s evidovanými komponentami už z pleistocénneho obdobia (polohy Ostrovské, Dlhé Diely, Očkov-Brehy: Žaár/Blašková 2012, obr. 2), eneolitu (Horné Brežné: Šuteková 2008; zrejme i Dlhé diely: Henzelyová/Kuzma/Rajtár 1997, 179; Klčo 2005), záveru doby bronzovej a doby halštatskej (Horné Brežné: Horñák 2016, 490) a významným polykultúrnym náleziskom $\mathrm{s}$ mohylou $\mathrm{z}$ mladšej doby bronzovej a germánskym žiarovým pohrebiskom patriacim do katastra susednej obce Očkov (najnovšie Kolník 2010, 626, 627). Rozprestiera sa na rovnakej terénnej vlne ako sledovaný areál v Hornom Brežnom. Plocha vyvýšeného terénu má charakter roviny s maximálnym sklonom do $3^{\circ}$ a plynulým klesaním do 2 metrov $\mathrm{k}$ hrane ostrohu. 


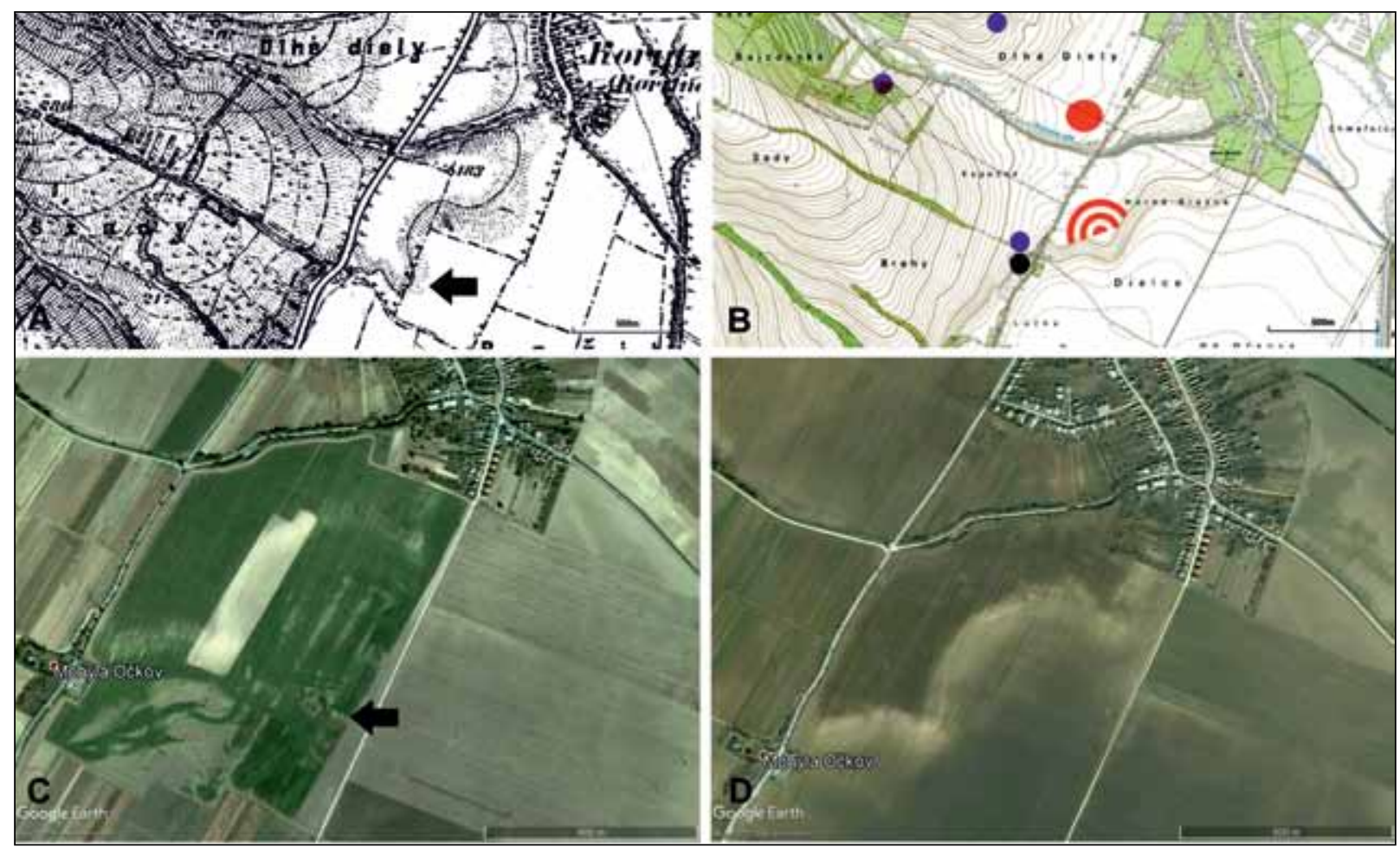

Obr. 2. Podolie, poloha Horné Brežné. A - pohl’ad na terén a sprašový ostroh v 19. storočí (III. historické mapovanie); B - lokalizácia archeologických nálezov z obdobia paleolitu (modrá), eneolitu (červená) a areál pamätníka v Očkove (čierna), pozri text; C - zaniknuté riečne rameno (snímka z roku 2003); D - sprašová terasa v Podolí (snímka z roku 2004).

\section{PODOLIE, POLOHA HORNÉ BREŽNÉ- DVA PRIEKOPOVÉ AREÁLY}

Obe priekopové štruktúry v polohe Horné Brežné boli vybudované na sprašovom ostrohu, ktorý ešte $\mathrm{v}$ druhej polovici 19. storočia výrazne vystupoval nad okolité alúvium (obr. 2: A; porovnaj obr. 2: D) a paleomeander Dudváhu, ktorý je aj v súčasnosti dobre viditel'ný na ortofotomapách či satelitných snímkach (obr. 2: C). Prvý menší priekopový areál je už z literatúry dobre známy (Šuteková 2008, 273, $274 ; 2010$, obr. 2). Ide o dve priekopy, každá v rozmeroch $3 \times 23,5 \mathrm{~m}$, ktoré boli od seba oddelené vol'ným nevyhíbeným úsekom. Híbka oboch objektov bola odlišná, severnejšia mala híbku $1 \mathrm{~m}$, južná $2 \mathrm{~m}$, obe s rovným dnom a viac menej zvislými stenami. Výskum z roku 1963 zachytil v ich okolí iba d’alšie dva malé jamy sídliskového charakteru, jeden s keramickými fragmentami a nádobou bošáckej kultúry (obj. 4/63) a druhý s lužickou keramikou (obj. 2/63) a kusmi z jednej strany plochej vyhladenej mazanice. Stopy po koloch alebo iné indície o existencii drevených konštrukcií sa v rozsahu sond nenašli. V. Němejcová-Pavúková uvádza v nálezovej správe (Němejcová-Pavúková 1968), že vo výplni priekop (obj. 1 a 3/63), ale i vo vyššie uvedenej bošáckej jame sa nad dnom alebo v zásype nachádzali kúsky roz- drvenej mazanice. Priekopy obsahovali vel'ké množstvo keramického materiálu, rekonštruovatelných nádob kuchynskej i stolovej keramiky vrátane črpákov, len niekol'ko kusov kamenných a kostených nástrojov, kamennú surovinu (Šuteková 2008, 280, obr. 3) a zopár výnimočnejších artefaktov vrátane dvoch slavónskych mís (Šuteková 2010, obr. 6; 7), zvieracie kosti (2500 kusov, podla Němejcová-Pavúková 1968) a zástupcov malakofauny. Na základe koncentrácie odpadu a jeho rozmiestnenia autorka predpokladá, že prirodzene zanášané priekopy (splachy v najspodnejšej vrstve a stredná farebne odlíšitelná vrstva $\mathrm{s}$ menším počtom nálezov) boli $\mathrm{v}$ závere zasypané intencionálne $\mathrm{v}$ krátkom čase aj s prehoreným odpadom (horná tmavá vrstva; Suteková 2008, 281).

V súčasnosti už poznáme lokalizáciu oboch objektov, ktoré ohraničovali len malý areál výbežku ostrohy $\mathrm{v}$ rozlohe okolo 0,45 ha so vstupom orientovaným na severozápad do otvoreného priestoru s pohladmi v smere na úpätie Čachtických Karpát. Ked’že bol pôvodný terénny výskum rozsahom obmedzený, nezachytil indície o prítomnosti akejkolvek d’alšej architektúry. Nález je interpretovaný ako opevnenie sídliska. Severne od skúmanej plochy v polohe Dlhé diely (obr. 2: B) bolo počas hlbokej orby v roku 1958 na ploche o výmere približne 


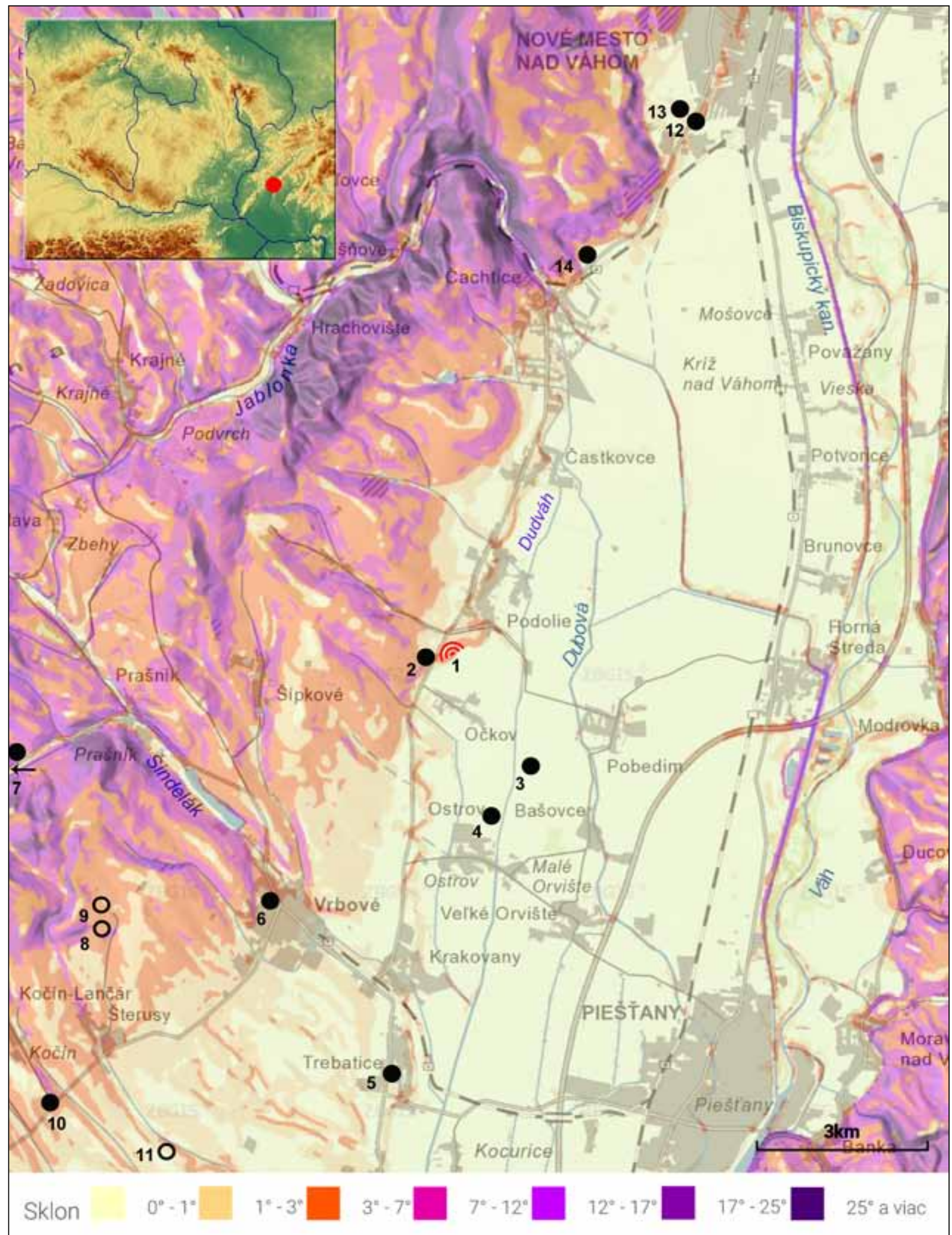

Obr. 3. Mapa lokalít spomínaných v texte (zdroj mapového podkladu ZBGIS s vrstvou - sklon terénu, s legendou). 1 - Podolie, poloha Horné Brežné; 2 - Očkov, poloha očkovská mohyla; 3 - Pobedim, poloha Hradištia; 4 - Ostrov, poloha Zábranie pri obecnom; 5 - Trebatice, poloha v intraviláne; 6 - Vrbové, poloha v intraviláne; 7 - Prašník, poloha Hrádok; 8 - Šterusy, rondel; 9 - Prašník, poloha Baraní majer (Od Bielku), rondel; 10 - Kočín-Lančár, poloha Dielce; 11 - Borovce, poloha Zadné pole, rondel; 12 - Nové Mesto nad Váhom, poloha Čachtická ulica; 13 - Nové Mesto nad Váhom, poloha Tri kríže; 14 - Čachtice, poloha Odmeštie. 
2 ha nájdený črepový materiál blízky bošáckej keramike, s crepmi zdobenými brázdeným vpichom, mazanica a zvieracie kosti. Archeologické nálezy sa nachádzali na ploche, kde sa vyrysovalo asi 20 až 30 tmavo sfarbených kruhovitých flakov - sídliskových objektov, ktoré sú zrejme identické s objektami zachytenými leteckou prospekciou $\mathrm{v}$ roku 1995 (Klčo 2005).

Výsledky geomagnetického nedeštruktívneho prieskumu odhalili existenciu dalších líniových štruktúr v celkovej dĺžke skoro 300 metrov, ktoré obopínajú areál v rozlohe okolo 2,9 ha. Rozpoznatel'né sú tri paralelné poloblúkové líniové útvary s dvoma prerušeniami siahajúce od jednej hrany terasy $\mathrm{k}$ druhej. Paralelné objekty sa javia ako rovnako široké. Predpokladáme, že ide o niekol'ko zahíbených objektov predstavujúcich lineárny systém priekop bez indícií o prítomnosti užšieho palisádového žlabu. Vo vnútri areálu sú viditelné desiatky anomálií, ktorých identifikovanie s archeologickými objektami je možné, ale je potrebné počítat' s geologickým alebo recentným pôvodom mnohých z nich (porovnaj Bošanský a i. 2012). Na tomto mieste je potrebné konštatovat', že doterajšie pozorovania povrchu pomocou leteckého alebo satelitného snímkovania nepriniesli žiadne pozorovania, ktoré by indikovali prítomnosṫ zahíbených objektov a priekop identifikovaných pomocou magnetometrie. Nakol'ko ide o polnohospodársky využívanú a obrábanú pôdu, je zaujímavé, že počas nepravidelne opakovaných návštev náleziska od roku 2006 sa na ploche štyroch až piatich hektárov neobjavoval na povrchu skoro žiaden nálezový materiál, resp. iba drobné atypické keramické fragmenty a recentný odpad $\mathrm{z}$ hospodárskej činnosti. To je v protiklade $\mathrm{s}$ údajom $\mathrm{v}$ odbornom denníku z roku 1963, kedy autorka terénneho výskumu spomína črepy na oboch častiach dvojitej ostrohy (Němejcová-Pavúková 1968) a zvýšenú koncentráciu črepov na mieste budúcich archeologických sond. Podla katalógu pochádzalo práve z vrstvy ", $0^{\prime \prime}$, resp. $\mathrm{z}$ úrovne tesne pod povrchom vtedajšieho terénu podobné množstvo črepov ako zo samotných objektov (vid’ Šuteková 2008, obr. 2). Súčasná situácia môže byt๋ výsledkom intenzívnych polnohospodárskych prác, ktoré cyklicky sa vynárajúce artefakty desatročia rozbíjali a ničili.

$\mathrm{V}$ prípade druhého líniového útvaru chýbajú t. č. záchytné body pre jeho bližšie časové zaradenie. $\mathrm{Na}$ základe formálnych a priestorových znakov nachádzame jeho najbližšie tvarové analógie v staroeneolitických michelsberských ohradeniach, ktoré v súčasnosti pribúdajú aj na území Čiech povodí Labe, Vltavy a Mže (podla Dobeš a i. 2016). K najstarším známym lokalitám patrí areál v obci Kly v okrese Mělník (Gojda (ed.) a kol. 2002, 386-388), ktorý je situovaný $\mathrm{v}$ podobnom type krajiny na sprašovej ostrohe vypínajúcej sa nad alúvium, pod ktorou mohol v minulosti pretekat' vodný tok. Areál v Klech však vymedzuje násobne väčšie územie (24 ha) ako v Podolí s vnútornou plochou len do 3 ha.

Rozlohou i formálnymi znakmi podobné priekopové ohradenia sú evidované aj na území mladšej eneolitickej kultúry Cham v Bavorsku a Rakúsku, tie však ohraničujú plochu do 0,8 ha s jednou výnimkou o rozlohe 3,2 ha (podla John 2010, 38-41). Vyznačujú sa stavbou jednej, maximálne dvoch priekop, čo sa približuje k súvekej analógii malej priekopy bošáckej kultúry v Podolí. Ako už bolo vyššie uvedené, rozpoznané trojnásobné líniové objekty v Podolí zatial' analógie na území Slovenska nemajú a súčasný stav poznania nás vedie $\mathrm{k}$ hladaniu analógií na území na západ od Karpát.

\section{ENEOLITICKÝ SÍDELNÝ AREÁL HORNÉHO DUDVÁHU}

Dobové poznatky z polohy Horné Brežné o výskyte bošáckeho črepového materiálu na povrchu celej ostrohy v 60 . rokoch 20 . storočia, povrchové nálezy eneolitickej keramiky z polohy Dlhé diely a zároveň analógie $\mathrm{v}$ prostredí mladoneolitických a eneolitických kultúr v západnej časti strednej Európy nás aj napriek nálezu lužického sídliskového objektu $\mathrm{v}$ blízkosti preskúmaných priekop bošáckej kultúry posúva argumentačne práve do obdobia eneolitu, kedy mohol byt novoobjavený lineárny priekopový objekt vyhíbený a funkčný. Tu vyjadrené domnienky môžu byt’ ovplyvnené našimi empirickými očakávaniami, ktoré má potvrdit alebo vyvrátit plánovaný terénny výskum.

Severný výbežok Podunajskej pahorkatiny patril vd’aka svojim podmienkam už v pleistocénnom období k pomerne intenzívne využívaným regiónom a tento trend pokračoval aj $\mathrm{v}$ nasledujúcich tisícročiach staršieho a mladšieho praveku. Mikroregión patrí do severnej zóny evidovaného osídlenia nositelov kultúry so starou lineárnou keramikou, pričom sídliská s dlhými domami kultúry s mladou lineárnou keramikou evidujeme aj v severnejšom Považskom Podolí, resp. v celej dížke vážskej doliny, vrátane Nového Mesta nad Váhom a Čachtíc (porovnaj Sedlák 2016, obr. 10). Na začiatku 5. tisícročia sa súčastou neolitickej krajiny širšej strednej Európy stávajú rondely ako špecifické kruhové priekopové areály v post-lineárnom, resp. lengyelskom kultúrnom prostredí, ktorým je v archeologickej literatúre už desatročiam venovaná vel'ká pozornost' (napr. Ř́dký 2011). V povodí Váhu patria k najsevernejším i najvyššie položeným známy lengyelský rondel v katastri obce Prašník (Kuzma/Tirpák 2006, 139) 
a o niekol'ko desiatok metrov južnejšie lokalizovaný objekt v katastri obce Šterusy (nepublikované, ústna informácia P. Milo a T. Lieskovský) s okolitým intenzívnym osídlením v mladom neolite i v období ludanickej skupiny. Počet rondelov v povodí Šteruského potoka (obr. 3) dopíňa aj objekt v Borovciach (Kuzma/Lieskovský 2007). Lokality sa koncentrujú najmä na juhovýchodnej strane Malých Karpát (podla Pažinová 2012, 118-120). V závere lengyelského osídlenia bolo v masíve Brezovských Karpát v polohe Prašník-Hrádok na ostrožnom výbežku vybudované výšinné sídlisko s centrálnou častou ohradenou palisádou (podla Bartík 2015, 27, 28). Ide o polohu s výbornou kontrolnou a strategickou funkciou v priestore malokarpatského priesmyku a o prvú evidovanú lokalitu s podobnými topografickými vlastnostami v sledovanom mikroregióne.

Porovnatelné trendy na území Trnavskej pahorkatiny smerom k Novému mestu nad Váhom pokračujú aj v eneolitickom období, kedy nálezy evidujeme najmä v povodí malokarpatských potokov a na sprašových terasách pozdĺž Dudváhu (obr. 3). Najviac nálezísk poznáme práve z úpätia Malých Karpát z katastrov obcí Chtelnica, Kočín-Lančár, Vrbové, Trebatice a Ostrov, ktoré vo väčšine predstavujú ojedinelé sídliskové komponenty, súbory črepov alebo artefakty, datované od epilengyelského obdobia až po mladý eneolit (porovnaj Sedlák 2016, obr. 9; 14). Sídliskové komponenty zo všetkých úsekov eneolitu pribúdajú aj severne v Považskom Podolí, čoraz viac v polohách s vyšším prevýšením, no taktiež ich poznáme z vyvýšených polôh v nive Váhu (Peška/Mellnerová Šuteková/Španihel 2019, 160-163). Vo vztahu k mladoeneolitickej bošáckej lokalite v Podolí je dôležité pripomenút aj blízkost' komponent $\mathrm{s}$ jevišovickým keramickým materiálom, z čoho významné je jediné jevišovické sídlisko s desiatkami sídliskových jám v katastri Kočín-Lančár a ostatné lokality z Vrbového a Trebatíc (viac porovnaj Šuteková 2008, 281), ktoré sú od Podolia vzdialené do $10 \mathrm{~km}$ vzdušnou čiarou s predpokladom limitovaných vizuálnych kontaktov. Sídlisko v Kočíne je situované v nadmorskej výške 227-240 m n. m.

Sledovaný mikroregión Horného Dudváhu bol $\mathrm{v}$ čase doby kamennej osídlovaný najmä na malokarpatských svahoch, na sprašových a riečnych terasách, zrejme aj na agradačných vyvýšeninách rieky Váh (napr. Pobedim). Vyššie položenou a ohradenou polohou je sídlisko v Prašníku vybudované v závere lengyelského obdobia, kedy sa osídlenie postupne rozširuje aj do polôh $\mathrm{s}$ vyšším prevýšením, ktoré v sebe kumulovali viac funkcií.

\section{DISKUSIA}

Súčasný stav bádania a naše poznatky o pravekej európskej krajine a jej sídelnej štruktúre potvrdzujú, že jej súčastou boli od počiatkov usadlého spôsobu života priekopové útvary ohradzujúce obytný areál, pričom sa mohli postupne formovat' dalšie ich funkcie $\mathrm{v}$ inej ako utilitárnej oblasti. V časoch rozvinutého neolitu evidujeme d’alšie viacnásobné priekopové, či palisádové areály zväčša kruhového pôdorysu, ktoré boli súčastou obytného alebo sídliskového areálu a mali výrazné monumentálne vlastnosti. Rondely (nem. Kreisgrabenanlagen) a rondeloidy sa v stredoeurópskej kultúrnej krajine objavujú nielen $\mathrm{v}$ prvej polovici 5 . tisícročia pred $\mathrm{n}$. 1., ale $\mathrm{v}$ rôznej dynamike aj v nasledujúcich úsekoch doby bronzovej a halštatskej, ako to nedávno sumarizoval A. Spazier (2017). V druhej polovici 5. tisícročia sa sídelný priestor všeobecne rozširuje aj do polôh vo vyššej nadmorskej výške a s vyšším prevýšením. Sú budované prvé ohradené, resp. opevnené výšinné sídliská s obytnými a d’alšími funkciami (k novšej diskusii o výšinných a/alebo opevnených lokalitách vo vnútrokarpatskom priestore od neolitu po dobu bronzovú pozri Dvorská Plháková a i. 2019, 40, 41; Peška/Mellnerová Šuteková/Španihel 2019). Súbežne s nimi sú budované priekopové stavby alebo ohradenia (anglicky causewayed enclosures), situované v rôznom type terénu, ktoré nevykazujú obytnú funkciu, a ktoré môžeme považovat za ideových pokračovatel'ov neolitických rondelov v pozmenenej formálnej podobe (napr. Turek 2012, 185-197). Tieto typy stavieb sa stali fenoménom pravekého sídelného priestoru v západnej časti Európy v oblasti korešpondujúcej s územím megalitických objektov a kultúrou s lievikovými pohármi, a formovali sa i v európskom vnútrozemí v post-vypíchanom období na hornom Dunaji a v stredonemeckej kultúre Michelsberg. Otázkam formovania, identifikácie, typológie priekopových areálov v kontexte zmien eneolitickej pravekej spoločnosti je v odbornej archeologickej literatúre venovaná značná pozornosṫ. $\mathrm{V}$ posledných rokoch už aj českými autormi, kedže počet priekopových areálov zo starého eneolitu vzrástol aj na území Čiech (Dobeš a i. 2016; viac Krištuf/Turek 2019). Ďalším obdobím, kedy sa podobné typy ohradení v západnej časti strednej Európy objavujú, je mladší úsek eneolitu na územi kultúr Cham, Bernburg i Jevišovice (viac John 2010, 35-40), ich vonkajšie, priestorové a chronologické vztahy sú vo väčšine prípadov ešte predmetom výskumu.

Interpretáciu priekopových areálov v Podolí bude nutné hodnotit vo vztahu k vyššie uvedeným 
skutočnostiam. Preskúmané priekopy s plochým dnom sú v súčasnosti interpretované ako opevnenie bošáckeho sídliska vyvýšeného nad okolitým úrodným alúviom (k terminológii pozri Peška/Mellnerová Šuteková/Španihel 2019, 158). Absentujú dáta o obytnej architektúre, resp. zvyšky väčších kusov mazanice sa $\mathrm{v}$ zásype priekop nenašli, ale nechýbajú prasleny, pracovné nástroje a zvieracie kosti, ktoré indikujú bežný sídliskový odpad. Nemáme poznatky o prítomnosti iných nálezov (ludské kosti alebo hovädzie lebky s rohmi), ktoré by ponúkali dalšie vysvetlenie. Priekopy v Podolí ohraničovali pomerne malý priestor (min. 0,45 ha), je to ale v súlade s poznatkami z územia Cham a Řivnáč, kde sa všeobecne predpokladá obytný charakter na lokalitách s menšou rozlohou (podla John 2010, 30) ale s existenciou sídelného areálu (polia, pastviny, výrobný areál atd.) v omnoho širšom priestore, za symbolickou hranicou obytného areálu.

Do priestoru v Podolí vstúpil d’alší priekopový areál $\mathrm{v}$ neznámom chronologickom vztahu $\mathrm{k}$ ostatným známym objektom, s formálnymi znakmi blízkymi staro- a mladoeneolitickým objektom zo západnej časti strednej Európy. Ak by išlo o tzv. sídliskovú fortifikáciu, otázna by bola jej reálna funkcia najmä vo vztahu k niekol'kým pomerne širokým vchodom otvoreným do rovinatého nechráneného terénu. Tento atribút je konštantný pre akékolvek praveké i historické obdobie.

Ak vyslovíme hypotézu o jeho eneolitickom datovaní, objekt by bol d’alším potvrdením existujúcich kontaktov medzi vnútrokarpatskou oblastou a územím na západ od Moravy. V prípade starého eneolitu zatial chýbajú na území Malých a Bielych Karpát nálezy potvrdzujúce prítomnost’ výrobkov alebo tovaru z prostredia na západ od Karpát, s kultúrou s lievikovými pohármi alebo kultúrou michelsberskou. Tie už naopak máme potvrdené z mladoeneolitického obdobia v prípade jevišovického sídliska v nedalekom katastri obce Kočín (okr. Pieštany) objaveného v roku 1985 (podla Šuteková 2010, 470, 471).

Z pohladu funkcie môže potvrdzovat' existenciu rovnakej symbolickej komunikácie vo forme nadkomunitných areálov a v nich prebiehajúcich aktivít aj v post-rondelovom období na našom území. Takéto areály boli budované a využívané $\mathrm{v}$ ostatnej časti širšej strednej Európy pravdepodobne v rôznych obdobiach praveku. Taktiež je relevantný priestorový vztah podolského nálezu k najsevernejšie položeným neolitickým rondelom $\mathrm{u}$ nás $\mathrm{v}$ okolí malokarpatského Prašníka, ktoré ležia južnejšie o necelých $10 \mathrm{~km}$ (obr. 3). Predmetné viacnásobné priekopové ohradenie z Podolia predstavuje zatial jediný a najsevernejšie situovaný útvar tohto typu z územia Slovenska.

\section{ZÁVER}

V skúmanom mikroregióne severnej časti Trnavskej pahorkatiny by sa mal výskum koncentrovat na identifikáciu súvekých sídliskových areálov v konkrétnych úsekoch praveku, sledovanie ich vzájomných chronologických vztahov a funkcií. Ide o územie využívané a osídlované kontinuálne od pleistocénu, kedy vznikali eolické sprašové terasy, v mladšom období formované meandrujúcim Váhom a jeho prítokmi. Nízke sprašové terasy tiahnuce sa od Nového Mesta nad Váhom juhovýchodným a juhozápadným smerom paralelne $\mathrm{s}$ pohoriami Čachtické Karpaty a Považský Inovec sú dobre čitatelné na reliéfnych mapách a vykazujú sklon priemerne do $7^{\circ}$ do pôvodnej riečnej nivy (obr. 3). Pre širokú vážsku nivu s agradačným valom boli na tomto území typické meandrujúce toky, mŕtve a slepé ramená rôzneho veku, ktoré obtekali a zrejme v rôznej intenzite tvarovali sprašové terasy. Takéto aktivity umocnené prirodzenou eróziou zrejme menili v zatial' neznámom čase a intenzite aj terasu v Podolí a Očkove. Pokračujúci terénny prieskum v Podolí bude zameraný na aplikovanie dalších metód nedeštruktívnej archeológie v polohe Horné Brežné ako aj Dlhé Diely, následne overenie datovania vel'kého priekopového útvaru a dokumentáciu jeho formálnych a priestorových vlastností, a to v kontexte historickej krajiny a environmentu.

\section{Pod'akovanie}

Za konzultácie v súvislosti s lokalizáciou rondelov d’akujem kolegom Ing. T. Lieskovskému, PhD. (Stavebná fakulta, STU v Bratislave) a doc. Dr. Phil. P. Milovi (Filozofická fakulta, Masarykova univerzita v Brne). 


\section{LITERATÚRA}

Bartík 2015 - J. Bartík: Hradiská z mladšej a neskorej doby bronzovej v Malých Karpatoch. In: P. Jenčík/V. Struhár (ed.): Hradiská - Svedkovia dávnych čias. Dolná Mariková 2015, 23-32.

Bošanský a i. 2012 - M. Bošanský/H. Stümpel/T. Wunderlich/M. Proksch/R. Pašteka/J. Mellnerová Šuteková: Geofyzikálny prieskum archeologickej lokality eneolitickej bošáckej kultúry pri Podolí. In: Študentská vedecká konferencia PriF UK 2012 [elektronický dokument]. Zborník recenzovaných príspevkov. Univerzita Komenského v Bratislave. Bratislava 2012, 1081-1085.

Bialeková 1990 - D. Bialeková: Hydrologické pomery v hornej časti dolného Považia vo včasnom stredoveku. Študijné zvesti Aú SAV 26, 1990, 115-127.

Dobeš a i. 2016 - M. Dobeš/P. Stránská/R. Křivánek/ P. Limburský: Časně eneolitické ohrazení ve Vliněvsi. Př́spěvek k povaze kontaktu mezi jordanovskou a michelsberskou kulturou v Čechách. Památky archeologické 107, 2016, 51-115.

Dvorská Plháková a i. 2019 - V. Dvorská Plháková/J. Mellnerová Šuteková/J. Vavák/P. Jelínek/J. Hlavatá/J. Bíšková: Eneolitická priekopa z Budmeríc, poloha Sušička. Zborník SNM 113. Archeológia 29, 2019, 31-45.

Gojda (ed.) a kol. 2002 - M. Gojda/D. Dreslerová/P. Foster/ R. Křivánek/M. Kuna/S. Vencl/M. Zápotocký: Velké pravěké ohrazení v Klech (okr. Mělník). Využití nedestruktivních metod výzkumu k poznání nového typu areálu. Archeologické rozhledy 54, 2002, 371-430.

Henzelyová/Kuzma/Rajtár 1997 - E. Henzelyová/I. Kuzma/ J. Rajtár: Pokračovanie leteckej prospekcie na juhozápadnom Slovensku. AVANS 1995, 1997, 77-82.

Horňák 2016 - M. Horňák: Sídliskové stratégie ludu lužickej kultúry na strednom Považí. In: L. Benediková/ J. Katkinová/V. Budinský-Krička: Ilava, poloha Porubská dolina. Pohrebisko lužickej kultúry na strednom Považi. Archaeologica Slovaca Monographiae. Studia 27. Nitra 2016, 454-506.

Ištok/Ižof 1990 - P. Ištok/J. Ižof: Podmienky vzniku a vývoja osídlenia krajiny dolného toku Váhu vo svetle geografických a archeologických prieskumov. Študijné zvesti Aú SAV 26, 1990, 145-168.

John 2010 - J. John: Výšinné lokality středního eneolitu v západních Čechách. Opomíjená Archeologie 1. Plzeň 2010.

Klčo 2005 - M. Klčo: Najstaršie osídlenie obce a okolia. In: J. Karlík (ed.): Podolie - história obce. Pieštany 2005, 17-25.

Kolník 2010 - T. Kolník: Stráže-Krakovany a Ostrovany/ Osztrópataka. Poznámky $\mathrm{k}$ novým súvislostiam a nálezom z hrobov germánskej elity. In: J. Beljak/ G. Březinová/V. Varsik (ed.): Archeológia barbarov 2009. Hospodárstvo Germánov. Sídliskové a ekonomické štruktúry od neskorej doby laténskej po včasný stredovek. Nitra 2010, 615-638.

Krištuf/Turek 2019 - P. Krištuf/J. Turek a kol.: Arény předků. Posvátno a rituály na počátku eneolitu = Ancestral Arenas. The Cult and Ritual at the beginning of the Eneolithic Period. Plzeň 2019.

Rukopis prijatý 28. 7. 2020

Translated by Juraj Mudrák and Jana Mellnerová Šuteková
Kuzma/Tirpák 2006 - I. Kuzma/J. Tirpák: Rondel v Prašníku. AVANS 2004, 2006, 139-140, 280.

Kuzma/Lieskovský 2007 - I. Kuzma/T. Lieskovský: Analysis of roundel visibility in GIS environment. Študijné zvesti AU SAV 41, 2007, 60-64.

Němejcová-Pavúková 1968 - V. Němejcová-Pavúková: Terénny výskum v Podolí, okres Trenčín, poloha Španiva. Nálezová správa AÚ SAV v Nitre č. 4408/68. Nitra 1968.

Pažinová 2012 - N. Pažinová: Bučany - Kopanice v kontexte lengyelského osídlenia Trnavskej pahorkatiny. In: J. Peška/F. Trampota (ed.): Otázky neolitu a eneolitu 2011. Mikulov - Olomouc 2012, 117-129.

Peška/Mellnerová Šuteková /Španihel 2019 - J. Peška/J. Mellnerová Šuteková/S. Španihel: Fortifikace eneolitu a doby bronzové na širším moravsko-slovenském pomezí. Vlastivedný zborník Považia 29, 2019, 153-188.

Rídký 2011 - J. Rídký: Rondely a struktura sídelních areálů $v$ mladoneolitickém období. Dissertationes Archaeologicae Brunenses/Pragensesque 10. Praha - Brno 2011.

Sedlák 2016 - M. Sedlák: Archeologická topografia Trnavskej pahorkatiny a dolnovážskej nivy v období praveku. Diplomová práca. Katedra archeológie, Filozofická fakulta UK v Bratislave. Bratislava 2016. Nepublikované.

Spatzier 2017 - A. Spazier: Das endneolithisch-frühbronzezeitliche Rondell von Pömmelte-Zackmünde, Salzlandkreis, und das Rondell-Phänomen des 4.-1. Jt. v. Chr. in Mitteleuropa. Forschungsberichte des Landesmuseums für Vorgeschichte Halle 10/I. Halle (Saale) 2017.

Šuteková 2008 - J. Šuteková: Opevnené sídlisko bošáckej kultúry (skupiny) v Podolí, okr. Nové Mesto nad Váhom (predbežná štúdia). In: I. Cheben/I. Kuzma (ed.): Otázky neolitu a eneolitu našich krajín 2007. Nitra 2008, 273-286.

Šuteková 2010 - J. Šuteková: Ein Einblick in die post-Badener Epoche in der Westslowakei. In: J. Šuteková/ P. Pavúk/P. Kalábková/B. Kovár (eds.): PANTA RHEI. Studies on the Chronology and Cultural Development of South-Eastern and Central Europe in Earlier Prehistory Presented to Juraj Pavúk on the Occasion of his 75. Birthday. Studia Archaeologica et Mediaevalia XI. Bratislava 2010, 469-489.

Turek 2012 - J. Turek: The Neolithic Enclosures in Transition. Tradition and Change in the Cosmology of Early Farmers in Central Europe. In: A. M. Gibson (ed.): Enclosing the Neolithic: Recent Studies in Britain and Europe. BAR 2440. Oxford 2012, 185-201.

Žaár/Blašková 2012 - O. Žaár/L. Blašková: Výsledky analýz sídliskovej štruktúry v mladom paleolite na strednom a dolnom Považí vzhladom na surovinovú základňu. Zborník SNM. Prírodné vedy 58, 2012, 15-25.

\section{ZDROJE MAPOVÝCH PODKLADOV}

ZBGIS: https://zbgis.skgeodesy.sk/ [30-06-2020].

Google Earth: https://www.google.sk/intl/sk/earth/ [30-062020].

Mgr. Jana Mellnerová Šuteková, PhD.

Katedra archeológie

Filozofická fakulta UK v Bratislave

Gondova 2

SK - 81102 Bratislava

jana.mellnerova@uniba.sk 


\title{
Eneolithic Settlement Area in Podolie near Nové Mesto nad Váhom
}

\author{
Ja na Mellnerová Šuteková
}

SUMMARY

The finds of Bošáca ceramics from the village cadastre in Podolie in the district of Nové mesto nad Váhom which originate from two ditches situated on the edge of a terrain wave, a kind of loess promontory, have been known in the archaeological literature since the 1970's. The field research in the so-called Španiva locality, the present-day Horné Brežné, was carried out in 1963 by V. Němejcová-Pavúková. The ditches used to demarcate a relatively small area at the very tip of the promontory, protruding over the paleo-meander of a waterway, which has disappeared in the present day. The research has unearthed a large amount of ceramic material, diverse artifacts and animal bones, which remains the largest collection of Bošáca finds in Slovakia to this day. The author of this study is dealing with the processing of the findings and the interpretation of the archaeological and cultural image (Šuteková 2008; 2010). A geophysical survey was carried out at the site in order to accurately locate the ditches in question, in which it succeeded (cooperation Prif UK in Bratislava and Institut für Gephysik, Christian-Albrechts-Universität zu Kiel). However, the survey with a range of almost 4 ha captured another large linear formation which took the form of three parallel linear anomalies forming a semicircular shape. The linear formation demarks a larger terraced area with the ends sloping towards its edges (Bošanský $a i$. 2012). These results are being published for the first time in archaeological literature (Fig. 1). The discovered linear structures probably represent the only such formation currently known from the territory of Slovakia, with analogies, from a formal viewpoint, west of the Carpathians in the post-rondel cultural landscape. The area of Podolie lies in the eastern foothills of the Čachtice Carpathians, on a loess terrace, which was in the past washed by meandering streams originating in the Little Carpathians, themselves tributaries of the Dudváh river (Fig. 2). From the geo-morphological point of view, it is a northern outcrop of the Danube Uplands, where the Váh river flows into the expansive plain of southwestern Slovakia and its flow slows down. In historical periods, it created a network of

Fig. 1. Podolie, site Horné Brežné. Reconstruction of the ground plan of the Bošáca culture ditch and the enclosures (drawing by J. Mellnerová Šuteková, source of map base ZBGIS).

Fig. 2. Podolie, site Horné Brežné. A - the view of the terrain and loess promontory in the $19^{\text {th }}$ century (the III. mapping in history); $\mathrm{B}$ - the spatial placement of the archaeological findings from Paleolithic period (in blue), Eneolithic (in red) and the area of the memorial in Očkov (in black), see more in text; $\mathrm{C}$ - the paleomenader (picture taken in 2003); D - the loess promontory in Podolie (picture taken in 2004). meanders and wetlands with its tributaries. The cadastre of Podolie belongs to an archeological sites which shows evidence of finds since the Pleistocene (sites Ostrovské, Dlhé Diely, Očkov-Brehy: Žaár/Blašková 2012, fig. 2), Eneolithic (Horné Brežné: Šuteková 2008; also Dlhé diely: Henzelyovál Kuzma/Rajtár 1997, 179; Klčo 2005), from Late Bronze Age and Hallstatt period (Horné Brežné: Horňák 2016, 490) an important poly-cultural site with a mound from the Late Bronze Age and a Germanic burials belonging to the cadastre of the neighboring village of Očkov (latest Kolník 2010, 626, 627). The mound in Očkov lies on the same terrain wave as the area we studied in Horné Brežné. The surface of the elevated terrain has the character of a plane with a maximum slope of up to $3^{\circ}$ and a smooth descent to 2 meters towards the edge of the promontory.

In the case of the second linear formation, we are currently missing significant clues to further specify its placement on the timeline. Based on formal and spatial features we can identify its closest analogies in shape in the ancient Neolithic Michelsberg enclosures, which are currently increasingly being found in Bohemia, around the Elba, Vltava and Mže river basins (after Dobeš $i$ a. 2016). Similar ditches can also be identified in the area of the younger Eneolithic culture of Cham in Bavaria and Austria, but these only demark an area of up to 0.8 ha, with one exception of 3.2 ha (after John 2010, 38-41). They are characterized by the construction of one or, at most, two moats, which is close to the modern analogy of the small Bošáca culture ditch in Podolie.

In the region of the northern part of the Trnava Uplands, research should focus on the identification of settlement areas, their chronological relations and functions (Fig. 3). An ongoing field research in Podolie will focus on the application of different methods of non-destructive archeology on the entire loess terrace in the position of Horné Brežné as well as Dlhé Diely. Attention will also be paid to the verification of the dating of the large trench formation and the documentation of its formal and spatial properties.

Fig. 3. Map with sites mentioned in text (source of ZBGIS with layer - terrain slope map, see legend). 1 - Podolie, site Horné Brežné; 2 -Očkov, site mound; 3 - Pobedim, site Hradištia; 4 - Ostrov, site Zábranie pri obecnom; 5 - Trebatice, site in urban area; 6 - Vrbové, site in urban area; 7 - Prašník, site Hrádok; 8 - Šterusy, roundel; 9 - Prašník, site Baraní majer (Od Bielku), roundel; 10 - Končín-Lančár, site Dielce; 11 - Borovce, site Zadné pole, roundel; 12 - Nové Mesto nad Váhom, site Čachtická street; 13 - Nové Mesto nad Váhom, site Tri kríže; 14 - Čachtice, site Odmeštie. 
